\title{
Turbo-charging tobacco control in South Africa
}

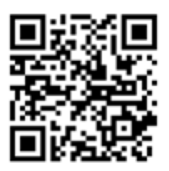

\section{Tobacco use globally and in} South Africa

Tobacco continues to be the leading cause of death and disease worldwide. ${ }^{[1]}$ Globally, the prevalence of smoking among adults decreased between 1980 and 2012 from $41 \%$ to $31 \%$ for men and from $11 \%$ to $6 \%$ for women, yet the number of smokers increased to nearly 1 billion by 2012. ${ }^{[2]}$ Tobacco use by girls is increasing in many countries, and unless effectively addressed will result in increased risk for the next generation of women. ${ }^{[3]}$ While media attention to global tobacco has waned, the harm it causes is increasing.

The 2015 World Conference on Tobacco or Health (WCTOH) held recently in Abu Dhabi recommended the urgent ratification of the World Health Organization (WHO) Framework Convention on Tobacco Control (FCTC) by the remaining non-signatories (of which the USA and Indonesia are the most significant), and full implementation of its provisions by all 180 signatory countries. ${ }^{[4]}$

After decades of neglect, South Africa (SA) emerged in the 1990s as a global leader in tobacco control. ${ }^{[5]}$ This began in 1993 with the Tobacco Products Control Act introduced by Rina Venter, the last Health Minister of the National Party government. It addressed smoking in public places, warnings on packaging and modest restrictions on advertising and sponsorship. In 1994, after the election of Nelson Mandela, Minister of Health Dr Nkozasana Zuma, along with Finance Minister Trevor Manuel, established tax and regulatory measures that have reduced the national prevalence of smoking - and saved many lives - in the years since. In doing so, Zuma made true on a pledge she made in the presence of ministers of health of Africa to take strong action on tobacco at the First All Africa Tobacco Control meeting in Zimbabwe in $1993 .{ }^{[5]}$ Thus started a decade of SA leadership steering African governments to play a key role in the drafting of the WHO FCTC negotiating process. SA leadership in tobacco control continues today as the FCTC moves from 'the books' to the streets. Policies to prevent tobacco use are proving effective: recent research shows that for each $\mathrm{R} 1$ increase in cigarette price, the risk of smoking initiation is reduced between $1 \%$ and $2.8 \%$ for males in SA. ${ }^{[4]}$

The latest study on tobacco use in SA shows that $17.6 \%$ of adults smoke ${ }^{[6]}$ Men have a higher prevalence of smoking than women: the male smoking prevalence is over three times greater than the female smoking prevalence of $7.3 \%$. Smoking prevalence differs greatly by race: $40.1 \%$ of coloured people smoke tobacco, including $34.4 \%$ of coloured women. This is nearly five times the prevalence among all SA women. Of students in grades $8-11$ in SA, $12.7 \%$ currently smoke cigarettes, including $10.8 \%$ of girls. ${ }^{[7]}$ This emphasises the reality that tobacco control remains a critical priority for the country.

\section{A turbo-charged approach towards a tobacco-free world}

A recent review of global approaches to tobacco control concludes that a 'turbo-charged' approach is needed, extending beyond the current rather leisurely pace of progress, to prevent the projected 1 billion tobacco deaths expected this century ${ }^{[3]}$ Several tactics are needed, especially in SA.

- Earmark tobacco taxes. Annual increases in tobacco excise taxes are needed that earmark $2-5 \%$ of such taxes to create a National Health Promotion Foundation as a private-public partnership involving leading insurers, retailers and other sectors committed to health. A model for SA to consider is the Thailand Health
Promotion Foundation (ThaiHealth), which uses 2\% of the alcohol and tobacco excise tax to fund health promotion and raises USD50 - 60 million annually. ${ }^{[8]}$ The Foundation has created a sustainable long-term source of funding to address chronic disease risks, including alcohol, tobacco, physical activity and diet, in settings that include schools, worksites and communities. Without such financing, tobacco control remains subject to the vagaries of policy makers and generally suffers.

- Tighten marketing regulations. Explicit attention is needed to block and weaken the marketing strategies used by the tobacco industry to target girls and women - these include brands with long, slim, low-tar and menthol products, and ads that depict slimness and sophistication. ${ }^{[9]}$ The FCTC provides for genderspecific regulations, but no countries have yet established these. A second marketing need is for SA to follow the lead shown by Australia and mandate plain packaging of tobacco products. The guidelines for implementation of Article 13 of the FCTC include plain packaging of tobacco products, a strategy that has been called for over a decade. ${ }^{[10]}$ The strength of the industry opposition to these measures, including World Trade Organization disputes, is the best evidence of their probable impact.

- Engage the private sector in tackling tobacco control. The private sector has played a key role in HIV/AIDS prevention and treatment and many other areas of public health, with benefit to their bottom line and society. Partnerships to address smoke-free workplace policies more effectively are just the start of what is possible. ${ }^{[3]}$ Retailers should be encouraged to follow the lead shown by CVS Health, a pharmacy that ended the sale of tobacco products from its stores in 2014. Rather than this having hurt business, CVS Health's stock price has increased by over $23 \%$ since 1 October 2014, when the policy was implemented. ${ }^{[1]}$ The efforts of Vitality, a health promotion programme, together with health and life insurance companies to support and incentivise members to end tobacco use should become the industry norm. ${ }^{[12]}$ Programmes run by insurers and retailers have the potential to positively benefit non-members and the broader society.

- Develop a harm reduction strategy that distinguishes between tobacco and nicotine. Controversy and misconception surround e-cigarettes, snus and related non-combustible products, driving doubt in the minds of smokers seeking to quit. Evidence suggests that this misinformation can reinforce a view that these products are no better, and possibly more dangerous, than traditional cigarettes. ${ }^{[13]}$ The worst example of this comes from the recent US Centers for Disease Control's new 'Tips from Former Smokers' campaign, and new California Health Department ads, that both fail to mention the simple reality that tobacco kills - before raising theoretical concerns about e-cigs. ${ }^{[14]}$ Evidence is increasingly showing the opportunity for e-cigs to improve public health and reduce the nearly 6 million global deaths due to tobacco use, as well as reduce healthcare spending resulting from tobacco. ${ }^{[1,15]}$ Research presented at the two latest global tobacco control research and policy meetings - the Society for Research on Nicotine and Tobacco meeting in Philadelphia ${ }^{[12]}$ and the World Conference on Tobacco or Health in Abu Dhabi ${ }^{[4]}$ - strengthened evidence of the benefits of e-cigs for smokers seeking to quit, and weakened concerns about young people using e-cigs as a gateway to eventual tobacco use. The Canadian Standing Committee on Health draft regulatory framework for e-cigs is worth considering. ${ }^{[16]}$ In the interim, SA health leaders - starting with the Minister of Health - would do well 
to emulate the approach taken by Jane Ellison, the UK Secretary of State for Health, when she repeated the recommendation of a statement carried by the Royal College of Physicians encouraging smokers seeking to quit to try e-cigs. ${ }^{[17]}$

\section{The way forward}

SA hosts the 17th WCTOH in Cape Town in 2018, placing a spotlight on the country's tobacco control policies and progress. SA has an opportunity to show global leadership by accelerating tobacco control in the country, and should use the time from now to 2018 to build a coalition of local players committed to demonstrate how a turbocharged approach can impact millions of smokers. We are ready to play our role.

\section{Derek Yach, Elle Alexander}

The Vitality Institute, New York, USA

\section{Corresponding author: D Yach (dyach@thevitalitygroup.com)}

1. Lim SS, Vos T, Flaxman AD, et al. A comparative risk assessment of burden of disease and injury attributable to 67 risk factors and risk factor clusters in 21 regions, 1990-2010: A systematic analysi for the Global Burden of Disease Study 2010. Lancet 2012;380(9859):2224-2260. [http://dx.doi. org/10.1016/S0140-6736(12)61766-8]

2. Ng M, Freeman MK, Fleming TD, et al. Smoking prevalence and cigarette consumption in 187 countries, 1980-2012. JAMA 2014; 311(2):183-192. [http://dx.doi.org/10.1001/jama.2013.284692]

3. Beaglehole R, Bonita R, Yach D, Mackay J, Reddy KS. A tobacco-free world: A call to action to phase out the sale of tobacco products by 2040. Lancet 2014;385(9972):1011-1018. [http://dx.doi. org/10.1016/S0140-6736(15)60133-7]

4. World Conference on Tobacco or Health, Abu Dhabi, UAE, 17-21 March 2015. http://www.wctoh.org/ body/Abstract-book-23-HD.pdf (accessed 6 April 2015)

5. Chapman S, Yach D, Saloojee Y, Simpson D. All Africa conference on tobacco control. BM] 1995;308:189. [http://dx.doi.org/10.1136/bmi.308.6922.189]
6. Reddy P, Zuma K, Shisana O, Jonas K, Sewpaul R. Adult tobacco use prevalence in South Africa: Results from the First South African National Health and Nutrition Examination Survey. S Afr Med J 2015;105(8):648-655. [http://dx.doi.org/10.7196/SAMJnew.7932]

7. Global Youth Tobacco Survey Fact Sheet. South Africa 2011. http://www.who.int/tobacco/surveillance/ gyts/en/ (accessed 22 June 2015).

8. World Health Organization. Thai Health Promotion Foundation. http://www.searo.who.int/tobacco/ news_events/thaihealth/en/ (accessed 6 April 2014).

9. World Health Organization. Female Smoking: The Tobacco Atlas. http://www.who.int/tobacco/en/

9. World Health Organization. Female Smoking: The Tobacco Atlas. http://www.who.int/tobacco/en/
atlas6.pdf (accessed 6 April 2015).
10. Yach D. Injecting greater urgency into global tobacco control. Tob Control 2005;14(3):145-148. [http:// . Yach D. Injecting greater urgency int
dx.doi.org/10.1136/tc.2005.011957]

11. Google Finance. CVS Health. https://www.google.com/finance?q=cvs\&ei=jiETVYHTDuqysAeX9YH YDA (accessed 25 March 2015)

2. Society for Research on Nicotine and Tobacco (SRNT). 2015. https://www.srnt.org/2015_SRNT_S-aa-G_G.pdf (accessed 23 June 2015).

13. Yach D. E-cigarettes save lives. The Spectator 2015;21 Feb. http://www.spectator.co.uk/health/featureshealth/cover-feature/9442271/e-cigarettes-save-lives/ (accessed 23 June 2015).

14. Alexander E Yach D. Distorted messages undermine tobacco control. Vitality Institute blog. http:// thevitalityinstitute org/distorted-messages-undermine-tobacco-control/ (accessed 23 June 2015).

15. Moody JS. E-cigarettes poised to save Medicaid billions. http://tobacco.ucsf.edu/sites/tobacco.ucsf.

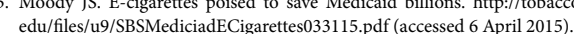

16. Canadian House of Commons. Report of the Standing Committee on Health. Vaping: Towards a regulatory framework for e-cigarettes. http://www.nsra-adnf.ca/cms/file/files/412_HESA_Rpt09-e.pdf regulatory framework for e-cigarettes. http://www.nsra-adnf.ca/cms/file/files/412_HESA_Rpt09-e.pdf (accessed 6 April 2015)

17. UK Parliament. Electronic cigarettes: Written question - 227133. http://www.parliament.uk/business/ publications/written-questions-answers-statements/written-question/Commons/2015-03-11/227133/ (accessed 6 April 2015).

\section{Further reading}

Reddy P, James S, Sewpaul R, et al. A decade of tobacco control: The South African case of politics, health policy, health promotion and behaviour change. S Afr Med J 2013;103(11):835-840. [http://dx.doi. org/10.7196/SAMJ.6910]

Yach D, Alexander E. Building partnerships for disease prevention and mobilizing resources for the global NCD agenda. In Public Health Approaches to Noncommunicable Diseases 2015 (in press). Wolter Kluwer. Guragon, India.

Yach D. The origins, development, effects, and future of the WHO Framework Convention on Tobacco Control: A personal perspective. Lancet 2014383(9930):1771-1779. [http://dx.doi.org/10.1016/S01406736(13)62155-8]

S Afr Med J 2015;105(8):637-638. DOI:10.7196/SAMJnew.8032 